\title{
PEDRO JOSÉ MARQUEZ EN EL RECUERDO Y EN LA CRÍTICA
}

\author{
P O R \\ JUSTINO FERNANDEZ
}

Al Dr. José Gaos

\begin{abstract}
T A figura del Padre jesuita Pedro José Márquez (1741-1820), si bien Lolvidada o poco conocida no ha dejado de ser tomada en consideración de una manera $u$ otra a lo largo del siglo xix y hasta nuestros días. Muchos han citado sus obras, pocos han contribuido a dar a conocer sus datos biográficos y menos aún han estudiado sus escritos y publicaciones.

Este trabajo no tiene más pretensión que ver cómo aparece el P. Márquez en el recuerdo y en la crítica, principalmente después de su muerte en México, para obtener asi el perfil intelectual del personaje tal como nos lo presentan algunos críticos, historiadores, bibliógrafos y hombres de ciencia, con la esperanza de que sus obras estético-arqueológicas, sean algún día estudiadas como se merecen.

Habremos de contentarnos, por ahora, con la información que se puede reunir en México, no tan escasa por cierto, que es el objeto principal de esta breve investigación.

En las Efemérides literarias de Roma se publicaron el año de 1806 dos artículos; el primero ${ }^{1}$ a propósito de la aparición de su opúsculo sobre "Dos monumentos de arquitectura mexicana" (1804), en el cual se reseña su contenido; el segundo ${ }^{2}$ versa sobre la traducción hecha

1 Efemérides literarias de Roma, No 29, de 19 de julio de 1806.

2 Efemérides literarias de Roma, № 41, de 11 de octubre de 1806.
\end{abstract}


por el P. Márquez al italiano (1804) de la obra de don Antonio León y Gama "Ensayo sobre la astronomía, cronología y mitología de los antiguos mexicanos". Ambos artículos fueron traducidos al español y recogidos por el Diario de México, en donde se publicaron en el año de 1808 el primero, ${ }^{3}$ y el segundo ${ }^{4}$ en 1809.

Ya se encontraba en México el P. Márquez cuando algunas de sus obras aparecieron citadas (1819) por don José Mariano Beristáin y Souza en su Biblioteca Hispano Americana Septentrional, ${ }^{5}$ precedidas de una nota biográfica en la cual constaba que "era maestro de latinidad en el Colegio del Espíritu Santo de Puebla" al tiempo de la expulsión de los miembros de la Compañia de Jesús en 1767, error que más adelante ha de rectificar don Francisco del Paso y Troncoso. Agrega Beristáin que "por su buen ingenio y bella literatura" mereció los títulos de Socio de las Academias de Madrid, Florencia y Bolonia. Las obras registradas por Beristáin son: Delle case di cittá degli antichi Romani; Delle ville di Plinio il giovane; y Due antichi Monumenti di Architettura Messicana.

Apenas transcurridos siete años después de la muerte del P. Márquez lo encontramos citado (1827) por el Barón de Humboldt en su Ensayo Politico sobre el Reino de la Nueva España, " quien refiriéndose a la pirámide de Papantla compara la teoría astronómica del P. Márquez sobre el número de nichos de aquel monumento, con otro argumento semejante de Gaterer, célebre historiador, acerca del número de habitaciones y de gradas en el gran laberinto egipcio.

Pero el primer artículo importante sobre el ilustre jesuita no aparece sino hasta 1854, escrito por uno de sus discípulos del Colegio de San Ildefonso, el no menos ilustre abogado don José Bernardo Couto, incluido en el Diccionario Universal de Historia y Geografia. ${ }^{7}$ Couto escribió la mejor biografía sobre el P. Márquez, en opinión de los que después de él la copiaron o utilizaron, con excepción de don Francisco del Paso y Troncoso quien se permite rectificar algún error y añadir nuevos datos, como veremos más adelante. Nos habla Couto de que el

3 Diario de México. 1808. T. Ix, pp. 105 y 106.

4 Diario de México. 1809. T. X, pp. 157 a 160 . La noticia de estos artículos está consignada por Medina en sus Noticias sobre jesuitas expulsos. Véase nota No 24.

5 Biblioteca Hispano Americana Septentrional, por José Mariano Beristáin y Souza. México, 1819. Vol. III, pp. 247 y 248. 1* Edic.

- Ensayo político sobre el Reino de la Nueva España, por el Barón de Humboldt. México, 1941. Sexta edic. castellana. Edit. Pedro Robredo. Vol. II, pp. 305 y 306.

7 Diccionario Universal de Historia y Geografia. México, 1854, Vol. v, pp. 143 y 144. 
P. Márquez enseñaba latinidad en el Colegio de Puebla cuando acaeció la expulsión, siguiendo en esto, sin duda, a Beristáin, como Paso y Troncoso ha de aclarar más tarde; que después de la expulsión "buscó en los libros honesta y útil ocupación", produciendo obras que le valieron la amistad aún de personas que tenían profunda ojeriza a los jesuitas, como don José Nicolás de Azara ${ }^{8}$ quien hubo al fin de reconocerle su valor. Por "el saber, la virtud y la gravedad" el P. Márquez es "una de las personas más espectables de la Orden", escribe Couto y agrega que a su regreso a México y ya en el Colegio de San Ildefonso, "los novicios encontraban en él un guía seguro".

Habla Couto con cierta emoción de la figura del viejecito venerable a quien conoció y trató como discípulo en los últimos años de su vida. Recomienda reunir y publicar en español las obras del que llama "Docto mexicano", tarea que él mismo se había propuesto llevar a cabo y que por desgracia no pudo cumplir. Al final del artículo agrega una bibliografía bastante completa del P. Márquez con resúmenes explicativos. Sosa dice que en manos de Couto quedaron sin publicar algunos manuscritos del P. Márquez. ${ }^{\circ}$ El bibliógrafo Brunet incluye en su Manual del librero (1862) ${ }^{10}$ cuatro de sus libros de arqueología clásica con una nota tomada de Cicognara (1857-61) que dice: "Los escritos de este sabio mexicano están llenos de erudición y merecen ser mencionados entre las obras más útiles y más instructivas que hay sobre las materias de que tratan".

Otro bibliógrafo, Leclerc, también menciona dos obras del P. Márquez en su Biblioteca Americana (1878), "1 por lo cual se ve que no sólo no dejaban de tomarse en consideración, sino que eran recogidas por los bibliógrafos importantes de la segunda mitad del siglo XIX.

En 1882 don Francisco del Paso y Troncoso reaviva el interés por la figura y las obras del jesuita, publicando en los Anales del Museo 12 su traducción al español del opúsculo sobre "Dos antiguos monumentos

8 Citado por don Martin Fernánclez de Navarrete en las Actas de la Academia de S. Fernando de Madrid. Opúsculos, t. 11, p. 300.

n D. Francisco Sosa da la noticia en su obra Biografias de Mexicanos distinguidos. Mixico, 1874. pp. 624 a 626.

10 Manuel du Libraire et de L'amateur des livres, por Jacques Charles Brunet. Paris, 1862. p. 1467.

11 Biblioteca Americana, por Ch. Leclerc. Paris, 1878. pp. 306 y 310.

12 Anales del Musca. 1882. T. II, p. 279. "Dos antiguos monumentos de Arquitectura Mexicana" (ilustrados). Por el P. Pedro José Márquez. Traducido y publicado por Francisco del Paso y Troncoso con notas bio-bibliográficas. 
de arquitectura mexicana", precedidos por una nueva nota bio-bibliográfica en la cual al referirse al artículo de Couto dice que es "un estudio biográfico tan acabado" que casi se limitará a extractarlo, agregando uno que otro dato del Catálogo de jesuitas (1871) ${ }^{13}$ y "rectificando un hecho, tomado sin duda de Beristáin, a quien hay que atribuirle el error". Se trata de que Beristáin asienta, como ya hemos dicho, que el P. Márquez enseñaba latinidad en el Colegio de Puebla al momento de la expulsión, pero es el caso que en el Catálogo antes mencionado se ve que el día del arresto formaba parte del Colcgio Máximo de México, de San Pedro y San Pablo, como escolar de Teología de primer año. A base del mismo Catálogo, Paso y Troncoso agrega nuevos y preciosos datos a la biografía de Couto, especialmente acerca de la primera etapa de la vida del jesuita, que en otro lugar recogeremos, y los completa con lo que ya aquél había asentado sobre el "Maestro de novicios".

El Museo Nacional, "primero en escuchar la voz de Couto". dice Paso y Troncoso, traduce y publica los "Dos antiguos monumentos..." por interesar a la arqueología mexicana, pero agrega que toca seguir el ejemplo a la Escuela de Bellas Artes. Amén de proporcionar la bibliografía del P. Márquez, la agrupa por materias y dice que tres de sus manuscritos se encuentran inéditos. Paso y Troncoso explica, además, que sólo ha traducido de la página primera a la veintinueve, del opúsculo citado, por "ser lo que interesa", ${ }^{14}$ ya que las apreciaciones del $P$. Márquez "tal vez no se vean con tanto interés como a principios de siglo, pero viniendo de un sujeto tan perito en Arquitectura deben tomarse en consideración y tal vez den luz" en tales asuntos.

En la segunda edición de la Biblioteca Hispano Americana de Beristáin (1883), ${ }^{15}$ se repite sin anotar o corregir el error de la primera y se dan los mismos datos bibliográficos.

13 Catálogo de los sugetos de la Compañia de Jesís que formaban la Provincia de México el dia de arresto 25 de junio de 1767. Contiene los sujetos por orden alfabético, por orden de edad, por orden de grado; los Colegios, las Misiones y los difuntos. Comenzado en Roma por D. Rafael de Zélis el dia 27 de junio y terminado el 23 de agosto de 1786. Imp. de I. Escalante y Cía. 18 7 . I Tomo en $4^{\circ}$

Parte de este Catálogo está reproducido como apéndice en la obra del P. José Mariano Dávila y Arrillaga, citada adelante en la nota No 19. El P. Méndez Plancarte dice (Véase Nota $\mathrm{N}^{\circ}$ 34) que el $\mathrm{P}$. Márquez fue quien continuó la obra de Zélis.

14 Lo incluido por Paso y Troncoso cs la parte central del opusculo que sc refiere concretamente a la Pirámide de Papantla y a la de Xochicalco.

15 Biblioteca Hispano Americana Septentrional, por el Dr. José Mariano Beristain y Souza. 24 edic. Pub. por el P. Fortino Hipólito Vera. T, II, 1883. p. 220. 
Don Francisco Sosa en su obra Biografias de mexicanos distinguidos (1874) ${ }^{16}$ dice del P. Márquez que son "Sus obras más conocidas en Europa que en su patria", que en el Colegio de San Ildefonso formó discípulos como don José Bernardo Couto, quien quiso traducir y publicar sus obras que quedaron en el olvido y quien conservaba sus manuscritos, como hemos dicho arriba; por último insiste en que las obras del jesuita deben de ser publicadas.

Hace la crítica don Marcelino Menéndez y Pelayo, en su Historia de las Ideas Estéticas en España (1886), ${ }^{17} \mathrm{del}$ discurso del jesuita "Sobre lo bello en general". Principia por decir que el opúsculo es, "al parecer, tan poco leido que ni siquiera hace mención de él el diligente Beristáin al tratar de otras obras de este autor, en la Biblioteca Hispano-Americana Septentrional"; y continúa diciendo que "sólo es notable por la confusión de ideas que en él reina"; que confunde la belleza con el agrado, definiéndola como "aquello en que el espíritu se complace", que "llega a usar como sinónimos las palabras belleza, verdad y bien" y exclama: "¡Cuán prolífico error, y cuán ineludibles sus consecuencias!"; que está lejos de la teoría de Arteaga ${ }^{18}$ y aun de toda racional Estética; que parece que en las últimas páginas de su discurso el $P$. Márquez vuelve sobre sí "y comprende que en la belleza debe de haber cierta incógnita cualidad, independiente de la verdad y del bien"; que el final del opúsculo parece arrancado de un diálogo de Platón y, por último, lo califica de "discurso archi-idealista y ontologista".

Al escribir la Continuación de la Historia de la Compañia del P. Alegre (1889), el Presbitero José Mariano Dávila y Arrillaga, transcribió la biografía formada por Couto sobre el $P$. Márquez, agregando algún dato más. También queda incluido el $\mathrm{P}$. Márquez en la Biblio-

16 Op. cit., véase nota No 9. También pub. Efemérides históricas y biográficas. Edic. El Universal. 2 vol. México, 1883.

17 Historia de las Ideas Estéticas en España. Menéndez Pelayo, Marcelino. Madrid, 1886. III, v. I. 269-272. Obras Completas. Segunda Edic. Madrid, 1903. T. v, pp. 112 a 115. T. vI, p. 319.

Historia de las Ideas Estéticas en España. Edic. Nacional de las Obras Completas de Menéndez Pelayo. Consejo Superior de Investigaciones Cientificas. Santander, 1940. Vol. III. Siglo xvul. pp. 174 a 176 y p. 558.

18 El P. Estevan de Arteaga es en opinión de Menéndez Pelayo una de las grandes figuras de la Estética de su tiempo. De su obra destaca las Investigaciones filosóficas sobre la Belleza Ideal considerada como objeto de los artes de imitacion, pub. cn Madrid en 1789, que "deben tenerse por el más metódico, completo y científico de los libros de estética pura del siglo xvir". 
thèque de la Compagnie de Jesus, (1890-1900), de Agustín y Aloys de Backer, S. J., publicada por Sommervogel. ${ }^{19}$

Don José Toribio Medina en su Biblioteca Hispano-Americana (1907) , ${ }^{20}$ cita sólo el discurso "Sobre lo bello en general" ( $N$ : 8026) $y$ dice que el $P$. Márquez fue mexicano $y$ autor de varias obras en italiano que imprimió en Roma de 1795 a 1808. Años después, al publicar La Imprenta en México (1911), ${ }^{21}$ describe dos opúsculos anónimos que pudieran atribuirse a la pluma del jesuita, uno de ellos es un "Piadoso devocionario en honor del Sagrado Corazón de Jesús", publicado en México en 1819 y el otro es una "Carta de agregación a la Congregación del Sagrado Corazón de Jesús", de la cual el ejemplar que tuvo Medina en sus manos tenía un sello de la Congregación, con fecha de 1819, suscrito al lado por el P. Márquez. En estas atribuciones sigue a Sommervogel (T. v. col. 604) y a Iriarte (T. 11. n. 1571).

En 1910 en el Diccionario de Geografia, Historia y Biografia Mexicana, ${ }^{22}$ de Leduc y Lara Pardo, aparece una nota biográfica sobre el P. Márquez, tomada de Couto, con una bibliografía, y en el mismo año se le cataloga como "Crítico de Arte", en la Antologia del Centenario, 23 formada por Urbina, Henríquez Ureña y Rangel; en ella se incluye una nota biográfica, también tomada de Couto, se transcriben íntegramente las opiniones de Menéndez y Pelayo arriba citadas y se añade una bibliografía.

Vuelve Medina a ocuparse del P. Márquez en sus Noticias de los jesuitas expulsos (1914), ${ }^{24}$ agregando algún nuevo dato biográfico $\mathrm{y}$ dando una bibliografía casi completa de la obra del jesuita, en la cual hace mención de: 1) una traducción inédita de los "Dos antiguos monumentos de arquitectura mexicana", hecha por Luis Ramirez, que

19 Continuación de la Historia de la Compania de Jesús en Nueva España del P. Francisco Javier Alegre, por el P. José Mariano Dávila y Arrillaga. Puebla, 1898. T. It, Agustin et Aloys de Backer, S. J. Bibliothèque de la Compagnie de Jésus. Edit. por Charles Sommervogel. Bruxelles. 1890-1900.

20 Biblioteca Hispano Americana. 1493-1810. Santiago de Chile. 1907. T. vir, pp. 153 y 154.

21 La Imprenta en Mexico (1539-1821), por José Toribio Medina. T. vill. Santiago de Chile. 1911, pp. 170 y 310.

22 Diccionario de Geografia, Historia y Biografia Mexicana, por Alberto Leduc y Dr. Luis Lara y Pardo. México, 1910. pp. 593 y 594.

23 Antologia del Centenario. Compilada por Luis G. Urbina, Pedro Henriquez Ureña y Nicolás Rangel. Primera parte (1800-1821). Mćxico, 1910. Vol. JI, pp. 876 a 880.

24 Noticias bio-bibliográficas de los jesuitas expulsos de América en 1767. Por José Toribio Medina. Santiago de Chile, 1914, pp. 225 a 228. 
paró en manos del propio Medina, ${ }^{25}$ y 2 ) una disertación sobre la vida de Mecenas, más extensa que el extracto que se imprimió ${ }^{2 B}$ y que el P. Márquez pensaba publicar completa. Repite, por último, la noticia sobre los dos opúsculos anónimos, antes citados. Antonio Palau y Dulcet reproduce la nota de Brunet e inserta la bibliografía del jesuita en su Manual del Librero (1926).

El P. Mariano Cuevas, S. J., en su Historia de la Iglesia en México (1928) , ${ }^{27}$ dice que "los últimos jesuitas mejicanos no tenían dinero para editar sus obras, sin embargo ... no faltaron mecenas... los escritos en latín, castellano e italiano, serán siempre unos imperecederos monumentos de la sabiduría de que abundaba la Provincia de México, tales... las sapientísimas (obras) sobre arquitectura del P. Pedro Márquez".

En 1914 aparece un pequeño folleto bellamente impreso sobre Pedro losé Márquez. Su vida y su obra. 1741-1941, 28 que el autor, Julio Orozco Muñoz, prologa de esta manera: "A mi tierra natal le dedico con fervor este elogio al más ilustre de sus hijos". En este opúsculo se dice que: "ni su nombre ni el de sus obras han sido tenidos hasta hoy a flor de labio por sus connacionales". La primera parte está dedicada a su biografía en la cual hay alguna discrepancia en el nombre de la goleta en que partió junto con otros jesuitas a la Habana, para pasar después a España e Italia, que dice haberse llamado "Santa Bárbara", mientras que Paso y Troncoso ${ }^{20}$ asienta que era una fragata llamada

25 Estuvo de venta en la Colección Ramírez, 482. Se anunció una traducción castellana inédita (Cat. Goupil. 125) que probablemente pasó a formar parte de la biblioteca del Conde de Benahavis y después de la de Medina. Traductor Luis Ramirez.

Datos en las Noticias de Medina. Véase nota 24.

20 Lo que se publicó fue sólo la Illustrazioni della villa di Mecenate in Tivoli. Roma, 1812.

27 Historia de la Iglesia en México, por el P. Mariano Cuevas, S. J. Tercera Edic. El Paso, Tex. 1928. Vol. Iv, p. 445.

28 Pedro José Márquez. Su vida y su obra. 1741-1941, por Julio Orozco Muñoz. Ediciones Historia y Poesía. México, 1941. Con un retrato del biografiado existente en la Presidencia Municipal de San Francisco del Rincón, Gto. Edic. de 100 ejemplares numerados, uno de los cuales, el Ne 69, me fue obsequiado por don Francisco Orozco Muñoz.

20 En la p. 19 del folleto habla el autor del Sr. Jesús Oliva y Orozco y dice que "se permitió hacer algunas anotaciones aclaratorias" al artículo de Paso y Troncoso (Véase nota No 12) que reprodujo el periódico El Centenario, órgano directivo de las fiestas del tercer centenario de la ciudad de San Francisco del Rincón, Gto. 
"La Flecha", en la que fue la 2?, expedición de jesuitas, № 210. Cita Orozco Muñoz lo que del P. Márquez escribió don Ignacio Ramirez, 30 a propósito de su exilio, a saber: "un designio oportuno para que su nombre pasara a la posteridad aureolado por la ciencia; y cuando en sus profundas nostalgias de expatriado, para olvidar su tierra y su familia, se entregaba al estudio y escribia sus meditaciones sobre el arte, labraba él mismo su imperecedera fama de hombre de ciencia y de corazón".

Agrega Orozco Muñoz que don Jesús Silva y Orozco, conterráneo del P. Márquez, escribió una biografía de él, ${ }^{31}$ asegurando que no fueron once las obras que produjo, como casi todos sus biógrafos asientan, sino veintidós. Que no fueron once en total lo prueba el que hay otra traducción de una obra suya publicada en los Anales del Museo ${ }^{32}$ y si hemos de creer que dejó algunos manuscritos inéditos es posible que a la postre el número crezca.

La segunda parte se refiere a la bibliografía del P. Márquez, enlistando las once piezas más o menos citadas por los biógrafos y bibliógrafos, si bien una de ellas, los "Apuntamientos por orden alfabético, pertenecientes a la Arquitectura, donde se exponen varias doctrinas de Marca Vitruvio Pollion" no es seguro que se haya impreso, según afirman varios, contra la opinión del $\mathrm{P}$. Gutiérrez Corral, quien dice vio la luz en tres volúmenes en 4", en 1806. El discurso "Sobre lo bello en general" no está enlistado como pieza independiente, sino en relación con la ficha de los "Esercitazioni architettoniche", porque alli se incluye la versión final en italiano, pero da la fecha (1801) y el lugar (Madrid) de la primera versión impresa en español. Termina esta parte Orozco Muñoz lamentándose de que hasta la fecha no se hayan traducido las

30 No da el autor la cita bibliográfica.

31 op. cit. (Nota No 28), p.

32 Nota en Ia p. 23 del folleto: A las obras anteriores hay que agregar el trabajo siguiente, "Observaciones del Padre Márquez acerca del Calendario del Códice Mexicano del Cardenal Borgia". Traducción del italiano por Jorge Engerrand. (Pllblicado en el Apéndice al T. III de los Anales del Museo Nacional de Arqueología, Historia y Etnología). México, Imp. del Museo Nacional de A. H. y E. 1912. El Dr. Nicolás León, en nota inserta al final del articulo, dice: "El original y una copia de este estudio, que no figura entre los escritos del P. Márquez citados por los bibliógrafos de Backer y Sommervogel, los encontré entre los papeles del Ilmo. Sr. D. Pelagio Antonio de Labastida y Dávalos, hoy en poder de su sobrino, el Ilmo. Sr. D. Francisco Plancarte y Navarrete. Está escrito en lengua italiana y lo tradujo a la castellana el Sr. Prof. Jorge Engerrand". 
obras del P. Márquez y hecho una edición definitiva de ellas, siguiendo en esto las ya tradicionales lamentaciones de un siglo de existencia, sobre este punto.

Al final del opúsculo que vengo reseñando se inserta una bibliografía con las obras de autores que han mencionado de una manera u otra al P. Márquez, o a sus escritos, lista interesante pero corta como puede verse por el presente trabajo que la amplía considerablemente. ${ }^{33}$

La penúltima e importante inserción del $P$. Márquez en una obra de conjunto fue hecha por el P. Gabriel Méndez Plancarte en su libro Humanistas del siglo xvirl ${ }^{34}$ en ella incluye una nota bio-bibliográfica en la que dice que presenta algunos pasajes del P. Márquez "interesantísimos por su acendrado mexicanismo". Estos pasajes a que se refiere están tomados de los "Due Antichi Monumenti..." y aparecen con estos encabezados: A la muy Noble, Ilustre e Imperial Ciudad de México; El filósofo, ciudadano del Mundo; Cultura de los antiguos mexicanos; Por qué ocultaban los indios sus monumentos; Los Sacrificios humanos; Los mexicanos y los griegos y, por último una curiosa disertación filosófica sobre El chocolate y la jicara.

Más adelante el $\mathbf{P}$. Méndez Plancarte incluye largos párrafos inteligentemente escogidos del discurso "Sobre lo Bello en general", traducidos por él del texto definitivo en italiano que apareció junto con los "Esercitazioni architettoniche...", más extenso que el de la edición madrileña de 1801. Respecto al conocimiento de las lenguas que el jesuita y esteta tenía, y a propósito del "Discurso", dice el P. Méndez Plancarte: "Por otra parte, el castellano del P. Márquez, si bien ofrece rasgos curiosos y expresiones no pocas veces pintorescas, adolece de graves defectos (muy explicables en quien tenía ya para entonces más de treinta años de vivir en Italia), defectos que Menéndez y Pelayo -con generosa, pero no laudable infidelidad- subsanó en los fragmentos que cita de este discurso. He decidido, pues, presentar mi versión del texto italiano -éste sí, elegantisimo- que fue la expresión definitiva del pensamiento estético de nuestro humanista".

Pero lo más interesante de lo escrito por el P. Méndez Plancarte sobrc el P. Márquez se encuentra en la introducción de su obra. Alude a los

33 No he podido localizar una de las publicaciones listadas. San Francisco del Rincón. El Tercer Centenario de su fundación. Por José María Murillo. México, 1907. En ella con seguridad se mencionará al $P$. Márquez.

${ }^{34}$ Humanistas del siglo xrirr. Introducción y selección de Gabriel Méndez Plancarte. Biblioteca del Estudiante Universitario. No 24. Edic. de la Universidad Nacional Autónoma. México, 1941. pp. 129 a 161 . Introducción: pp. Xxi a xxill. 
pasajes que ofrece del casi ignorado discurso "Sobre lo bello en general", que por primera vez se dan a conocer en español y que quizá Menéndez y Pelayo no conoció; califica el juicio de éste sobre aquel opúsculo, de "adverso" y excesivamente "sumario" pues estima que "son rectas sus apreciaciones fundamentales (del P. Márquez) y no encuentra la "confusión de ideas" que en él veía reinar el gran crítico español. Hace la defensa del "discurso" del P. Márquez diciendo que:

"En sustancia, la definición que de la Belleza propone Márquez coincide con la comúnmente admitida por los antiguos Escolásticos: la perfección de las cosas en cuanto que deleita -con placer puro y desinteresado- el ánimo de quien las contempla. Pero hay en nuestro humanista, como en tantos otros de los estéticos españoles, además del elemento puramente intelectual que procede del aristotelismo escolástico, un fervor emotivo y casi místico de indudabla origen platónico: así, el magnífico elogio de la luz - que no sabe envejecer»-, inspirado directamente en los neoplatónicos alejandrinos; así también, el párrafo final, cuyas palabras - según confesión del propio Menéndez y Pelayo- "parecen arrancadas de un diálogo de Platón». $\mathrm{Y}$ aunque el $\mathrm{P}$. Márquez exige con insistencia el acatamiento a las leyes inmutables de la razón, bastarían las férvidas alabanzas que tributa a ala novedad como engendradora de belleza para convencernos de que no es un frío razonador académico, sino un profundo y delicado artista.

"De gran valor, asimismo, parécenme sus certeros atisbos acerca del elemento subjetivo -ideas o prejuicios nacionales, costumbres, tradiciones antiguas- que tanto influyen en la percepción de la belleza. Y sumamente curiosa, su apología de la hermosura varonil y de su victoria sobre la belleza de "las señoras mujeres».

"Lo que a Menéndez y Pelayo - defensor acérrimo del arte puro en contra del pretendido arte docente, que ni es arte ni enseña nadadisgustó, sin duda, en el discurso del P. Márquez, fue la identificación que éste firma entre belleza, verdad y bondad. Pero su desazón y mal humor se habrían quizá disipado con sólo recordar lo que él, mejor que nadie, sabia: el origen platónico de tal identificación, verdaderísima en el plano ontológico y en Dios, suprema cumbre y fuente primera del Ser, pero falsa en el orden meramente lógico y en el terreno artístico, donde la belleza no necesariamente va unida a la verdad lógica ni a la bondad moral. 
"Hecha esa salvedad - necesaria, por lo demás, en el mismo Platón, inmortal fundador de la ciencia de lo Bello-, creo que la disertación estética de nuestro humanista no es indigna de un verdadero filósofo que había apacentado largamente su espíritu en la contemplación de las reliquias de la Roma Cesárea, contribuyendo con sus obras «a difundir el gusto de la crítica arqueológica y de la arquitectura clásica», pero que sabía, a la vez, apreciar -con amplitud de gusto no frecuente en su época- la hierática majestad y la sabiduria arquitectónica de nuestros monumentos precortesianos".

Soy consciente de que estos apuntes bibliográficos sobre el P. Márquez no están ni remotamente completos, amén de citas desperdigadas quizá en periódicos y revistas europeas o mexicanas me faltaría consultar otras obras citadas por Medina, ${ }^{35}$ que no he podido tener a mi alcance: "Jesuitas expulsos literatos en Italia".-Por Madariaga.- Con apéndices, Salamanca. 1897; "L'inmigrazione dei Jesuiti spagnoli litterati in Italia". Por Cian Vittorio. Torino, 1895; la bibliografía de Raimundo Diosdado Caballero, quien aprovechó la obra del P. Luis Rizzi, "Noticia degli scritori Gesuiti i quali dopo l'abolizione de la Compagnia hanno publicato diverse opere", asi como las bibliografías de Cicognara, Sommervogel y de Uriarte, etcétera, etcétera, pero de todos modos no las juzgo indispensables, primero, porque mi propósito no es formar una bibliografía exhaustiva a este respecto, sino más bien sondear la atmósfera del recuerdo y de la crítica en que se han considerado las obras y la figura del P. Márquez y, segundo, porque las obras arriba mencionadas ya fueron consultadas por los bibliógrafos que yo he revisado y por lo tanto no creo que arrojen datos novedosos.

Quedan pendientes, por el momento, otras informaciones interesantes, por ejemplo las fechas de ingreso a las Academias europeas a que el P. Márquez perteneció y datos relativos a éste y otros asuntos; pero, sea como sea, lo que aquí se presenta es más de todo lo que independiente y fragmentariamente se ha publicado.

Es tiempo de recoger las notas de esta pequeña investigación para dibujar el interesante perfil del P. Márquez, según ha ido formándose durante siglo y medio, desde la aparición de su primera obra. 
A mediados del siglo xix la publicación más conocida del P. Márquez es sin duda sus "Due antichi monumenti di archittetura messicana", que debe haber llamado la atención por el asunto de que trata, siguiéndola en interés la traducción de la obra de León y Gama "Saggio dell Astronomía, Cronologia e Mitologia degli antichi Messicani" (conocida vulgarmente por "Las Dos Piedras"). Mas, en la segunda mitad del siglo prácticamente todas sus obras eran ya bien conocidas, sobre todo en Europa más que en México, como dice don Francisco Sosa, particularmente las de Arqueología clásica.

En nuestro siglo no sólo las fichas de sus publicaciones son recogidas en las mejores bibliografías, sino que se agregan noticias de algunas otras y de sus manuscritos inéditos. Pero si bien las citas abundan creo que el P. Márquez fue más leído en su propio tiempo y hasta cierto punto en nuestros días, no popularmente sino por eruditos. Prueba de lo anterior es que Menéndez y Pelayo hace la crítica de su discurso "Sobre lo bello en general", justamente hasta un siglo después de su aparición y casi un siglo y medio después, es decir en nuestro tiempo, se publican por primera vez en español algunos fragmentos del mismo opúsculo y los incluye el P. Méndez Plancarte en sus "Humanistas del Siglo XvıI". Las opiniones vertidas en la segunda mitad del siglo XIX, antes de Menéndez y Pelayo, tienen el aire de la fama del P. Márquez, están llenas de entusiasmo y admiración pero no de sana crítica. En general, puede decirse que nuestro jesuita, en siglo y medio, es más famoso que conocido a fondo y más leído superficialmente que estudiado. Lo dicho no debe extrañar, pues además de que sus obras no podían tener aceptación amplia por su indole misma, están escritas en italiano y no han sido traducidas; son publicaciones que se catalogan entre los "libros raros".

En los primeros años de la pasada centuria aparecen reseñas de sus trabajos, ya como autor original ya como traductor de una de las importantes revistas literarias de Italia y en el Diario de México, como hemos visto. Después lo citan los grandes bibliógrafos americanos y curopeos: Beristáin, Brunet, Leclerc, Cicognara, de Backer, Sommervogel, Iriarte, Diosdado, al fin Medina y Palau y Dulcet. ${ }^{30}$

Se le conoce "por su buen ingenio y bella literatura", como socio de las Academias de Bellas Artes de Florencia, Bolonia, Roma, Madrid y

36 Manual del Librero Hispano-Americano, por Antonio Palau y Dulcet. Barcelona, 1926. Vol. v, p. 66. 
Zaragoza; se le compara con los historiadores célebres y se le cita por sus teorías astronómico-arqueológicas.

A mediados del siglo le recuerdan sus discípulos con cariño y admiración; Couto escribe su biografía y da a conocer su bibliografía; se pretende traducir y publicar en español todas sus obras; se sabe que "buscó en los libros honesta y útil ocupación"; que alcanzó la amistad y el reconocimiento aún de personas enemigas de los jesuitas; se le reconoce su saber, virtud y gravedad, haber sido "un guía seguro para los novicios" y "una de las personas más espectables de la Orden".

Alcanza fama mundial como "sabio mexicano" y de sus obras se dice que están llenas de erudición y que merecen ser mencionadas "entre las más útiles y más instructivas", en las materias que tratan.

En el último cuarto de la centuria se traduce parte de su opúsculo sobre los "Dos monumentos de arquitectura mexicana" y la publica el Museo Nacional, si bien ya se piensa que sus apreciaciones "tal vez no se vean con tanto interés como a principios de siglo", entre otras cosas porque los estudios arqueológicos habían avanzado; se le llama "Maestro de novicios" y se insiste en que sus obras sean traducidas y publicadas, por haber sido un "perito en arquitectura".

Se le incluye entre los mexicanos distinguidos; en la Historia de la Compañía aparece como sujeto notable por sus escritos; se dice que es más conocido en Europa que en su patria y se renueva insistentemente la idea de darlo a conocer aquí; que pasará a la posteridad porque se labró imperecedera fama y se le considera como hombre de ciencia y de corazón. Sus escritos piadosos circulan anónimamente.

Al fin del siglo xix el panorama de apreciación cambia un tanto. Aunque "poco leído", Menéndez Pelayo incluye su discurso "Sobre lo bello en general" en su monumental Historia de las Ideas Estéticas en España; dice de ese opúsculo que es "sólo notable por la confusión de ideas que en él reina", lo considera en parte inspirado en Platón y lo tacha de archi-idealista y ontologista; sin embargo, le reconoce que contribuyó con otros a difundir el gusto por la crítica arqueológica y de la arquitectura clásica.

Se le cita como autor mexicano; como "crítico de arte" aparece en la Antología del Centenario, pero en vez de estudiar su obra se transcriben las opiniones de Menéndez Pelayo. Se dice que escribió más obras de las que se conocen y se le llama "ilustre hijo de San Francisco del Rincón". Se recuerda, ya en nuestros días, que sus obras han caído en el olvido 
y si bien antes se insistía en que se publicaran en español, ahora se lamenta que no se haya llevado a cabo la idea.

El P. Cuevas califica de "sapientísimas" sus obras. El P. Méndez Plancarte destaca su "acendrado mexicanismo"; observa que su castellano es a veces pintoresco y defectuoso pero que su italiano es elegantísimo; es el primero en hacer la defensa del "Discurso" contra las opiniones de Menédez y Pelayo y lo incluye entre los humanistas del siglo xvin. Por último, esta breve investigación se produce con intenciones de levantar el interés por estudiar su obra, por ser el P. Márquez el único jesuita mexicano de su tiempo que se dedicó al estudio de la arqueología clásica y a la mexicana, así como a la estética, y su figura descuella en esos campos al revisar el cuadro de las disciplinas en que se ocuparon los miembros de la Compañía en el siglo xvir.

Si pues las obras del $P$. Márquez han podido vivir, de una manera $\mathbf{u}$ otra, por espacio de siglo y medio, en el recuerdo y en la crítica; si han sido citadas en tantas publicaciones europeas y americanas; si fue conocido en el mundo de la cultura y dio fama a nuestro país por ser considerado como un "sabio mexicano"; si se le reconocieron su saber y virtudes; si se ocuparon de sus ideas hombres notables; si en importantes instituciones europeas se le admitió con beneplácito, ¿cómo es posible que en su propio pais no se le haya estudiado, a lo menos para tener conciencia de sus méritos o debilidades? Si en el siglo xix se insistió que se tradujeran y publicaran sus escritos y si en nuestros días ya sólo nos lamentamos de que eso no se haya hecho, procuremos pagar la deuda que debemos al intelectual que por tan largo tiempo vivió fuera de su suelo natal y que, sin embargo, conservó vivo el amor y el interés por México honrándolo con su pluma. Amén de los estudios que sobre él se hagan, publiquese a lo menos una Antología de sus escritos, bien seleccionadas las partes de mayor interés, porque publicarlos todos integramente parece difícil y fuera de tiempo y seguir lamentándose no conduce a sitio alguno. De una cosa se puede estar seguro y es que la Historia de la Cultura Mexicana no puede dejar pasar desapercibida la figura del Padre jesuita Pedro José Márquez. ${ }^{37}$

Cuando tuve el privilegio de formar parte de un seminario del ilustre filósofo y maestro doctor José Gaos, hace unos veinte años, el tema

37 Hoy dia (1962) se proyecta publicar un volumen dedicado al P. Márquez en la Biblioteca del Estudiante Universitario. 
propuesto a consideración fue replantear el problema de la Historia Cultural de América y especialmente la de México. Entonces el doctor Gaos animó a un grupo de estudiosos para que investigaran el movimiento cultural jesuita de los siglos xvir y xvin. Me tocó en suerte ocuparme del P. Pedro José Márquez y si bien los estudios que hice no llegaron a tener resultados concretos, se clespertó en mí el interés y la admiración por su obra, por referirse a la arqueología mexicana y a la clásica, así como a la estética, pero no he podido trabajar en el tema.

En tres ocasiones me he ocupado de las ideas del P. Márquez; la primera en un artículo titulado Goya contemporáneo, 1946; ${ }^{38}$ la segunda en $\mathrm{mi}$ libro Arte Moderno y Contemporáneo de México, 1952; ${ }^{39}$ la tercera en Coatlicue, 1954 y 1959. ${ }^{*}$ En pocas palabras, puedo decir que procuré situar el Discurso sobre lo Bello en general en relación con las ideas estéticas más importantes en el tiempo en que se publicó la versión en español, 1801, y que puse de relieve la intención del P. Márquez de equiparar las culturas indígenas de América a la antigüedad clásica. Sobra decir que el juicio de Menéndez y Pelayo me parece inaceptable y que tan sólo el P. Gabriel Méndez Plancarte se ha acercado a la obra del P. Márquez con la más amplia comprensión. A las notas consideradas más arriba, puede el interesado agregar estas últimas mías, que vienen a completar y a poner al día la información sobre cómo ha sido considerado el P. Márquez y sus obras en el recuerdo y en la crítica.

38 Fernández, Justino. "Goya Contemporáneo". Filosofia y Letras, 23. UNAM. Mixico, 1946 .

39 Fernández, Justino. Arte Moderno y Contemporaneo de Mléxico. Instituto de Investigaciones Estéticas, UNAM. México, 1952.

40 Fernández, Justino. Coatlicue. Estética del Arte indigena Antiguo Instituto de Investigaciones Estéticas, LNAM. México, 1959 (2a edic. La $1^{n}$ ellic. es de 1954). 